\title{
Thermal Fatigue Of Die-Casting Dies: An Overview
}

\author{
Hassan A. Abdulhadi ${ }^{1,2 a}$, S.N. Aqida ${ }^{2}$, M. Ishak ${ }^{1}$, G. R. Mohammed ${ }^{1,2}$ \\ ${ }^{1}$ Faculty of Mechanical Engineering, University Malaysia Pahang 26600 Pekan, Pahang, Malaysia \\ ${ }^{2}$ Baghdad-Institute, Foundation of Technical Education, 10001 Baghdad, Iraq
}

\begin{abstract}
Coupled studies by experimental and numerical simulations are necessary for an increased understanding of the material behaviour as related to the interaction between the thermal and mechanical conditions. This paper focus on the mechanisms of thermal fatigue in the failure of dies and cores used in the die casting of aluminum alloys. The thermal fatigue resistance is expressed by two crack parameters which are the average maximum crack and the average cracked area. Samples of various types of H13 steel were compared with a standard H13 steel by testing under identical thermal fatigue cycles. To determine the thermal constraint developed in the sample during the test, a finite difference technique was used to obtain the temperature distribution, based on temperature measurements at the boundaries. The resulting stresses and strains were computed, and the strain calculated at the edge or weakest point of the sample was used to correlate the number of cycles to crack initiation. As the strain at the edge increased, the number of cycles to failure decreased. The influence of various factors on thermal fatigue behavior was studied including austenitizing temperature, surface condition, stress relieving, casting, vacuum melting, and resulfurization. The thermal fatigue resistance improved as the austenitizing temperature increased from 1750 to $2050^{\circ} \mathrm{F}$.
\end{abstract}

Keywords:; Aluminium alloys, air entrapment; die molten metal, materials

\section{INTRODUCTION}

Die soldering is the result of an interface reaction between molten aluminium and the die material during the impact of the high velocity molten aluminium onto the die surface and the intimate contact between alloy and die at high temperature. Once molten aluminum gets into the die with high motion, it destroys the protective film (lubricant and coating) on the die surface, it reaches the primal die surface. Then, the iron dissolves into the molten aluminum and a layer of inter metallic phases appears. A soldering layer, which is difficult to prevent, is formed over this intermediate layer at an atomic level. The adhesion of the cast metal to the die surface or core is recognized as soldering,which happens by different changing reactions along with the solidification phase, because of the dependence on die layer and the aluminum alloy. The chemical reactions take place because of the formation of intermetallic layers at the die substrate. Soldering is the resulting buildup of the aluminum alloy which takes place at the interface. During expulsion casting, soldering will create some adhesive problems which can even worsen to the extent of sticking wear, depending on the separation of the casting from the die $[1,2]$.

Washout of aluminum die-casting dies is basically caused by erosive and corrosive wear, and soldering. They are the main reasons of damage to the die surface and excessiv washout will eventually lead to the catastrophic they die. Corrosive wear can be best defined as the resolution of the die material in the molten aluminum and the stabilization of intermetallic substrate [3-5]. Corrosion occurs from high die temperatures which caused surface oxidation, at which point the alloying elements are soluble in liquid aluminium. Thus, the intermetallic material can form at the die surface. The main mechanism of erosionis because of liquidencroachment erosion. Initial Si particles, oxide corpuscles, and impurities or intermetallic particles happen by filling solid erosion in result of the impact of solidified particles. When there is a highspeed flow of molten metal related to the die surface, erosion takes place. It gets further severe in the presence of hard particles like primary solid silicon in 390 alloys or $\mathrm{SiC}$ particles in metal matrix composites. Chemical corrosion is known as the process of material penetration and dissolution by the malt as well as the interface layer formation, when there is a trivial relative motion between the solid materials and the melt Gross cracking is normally devastating which might lead to a complete cracking of the die. Cracking and die fracture take place when the die material is stressed over its fracture strength as shown in Figure1. This can happen even when the mechanical stress applied to the die is less than the yield stress. A compound of residual, thermal and mechanical stresses create the crack [6-8]. This kind of failure is attributed to the inherent resistance of the die material against the brittle fracture termed fracture toughness.

\section{DIE-CASTING DIES FAILURE MECHANISM}

Roughly half of the aluminium alloys castings which are produced all through the world by the use of gravitational die casting or high pressure die casting (HPDC) are used in different automotive parts and consumer goods[9-13]. One of the major concerns in die casting is the durability of die materials/surface when they are exposed to pressurised casting process during filling, high temperature molten aluminium flow, and solidification and die holding stages $[14,15]$. In die

casting process, the molten aluminum alloy is injected into die cavity at high speed of $30-100 \mathrm{~m} / \mathrm{s}$, at temperatures between 670 $710{ }^{\circ} \mathrm{C}$, and injection pressure of $50-80 \mathrm{MPa}[3,4,8,16,17]$. Several failure modes appear on aluminum die casting surface such as soldering effe.cts, washout gross-cracking (cleavage cracking) and thermal fatigue cracking which happen in effect of heat checking [18-20] . 

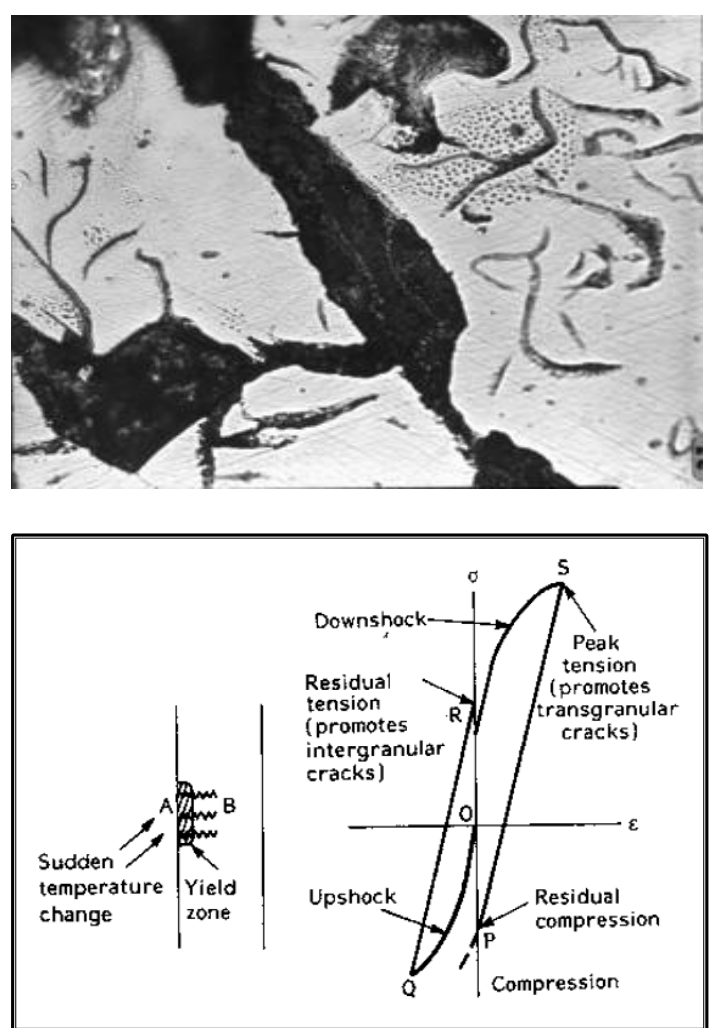

Figure 1.Hysteresis loop at the surface of a material subjected to cyclic heating cooling [18]

Moreover, die-casting dies are prone to high mechanical and thermal loads. Thermal fatigue cracking of dies which is caused by thermal cycling might considerably reduce the die lifetime. Cracks reduce the surface quality of dies and consequently the surface of castings will decline too. Previous studies have analysed thermal fatigue cracking of dies during the process of die casting aluminium alloys [7, 8]. During the process cracks are identified and their size and location are measured. Thermal and mechanical loads produce high local stresses which make the surface to crack. First cracks emerge right after 2000 cycles and spread progressively with cycles as illustrated in Figure1. [7, 18, 20, 21]

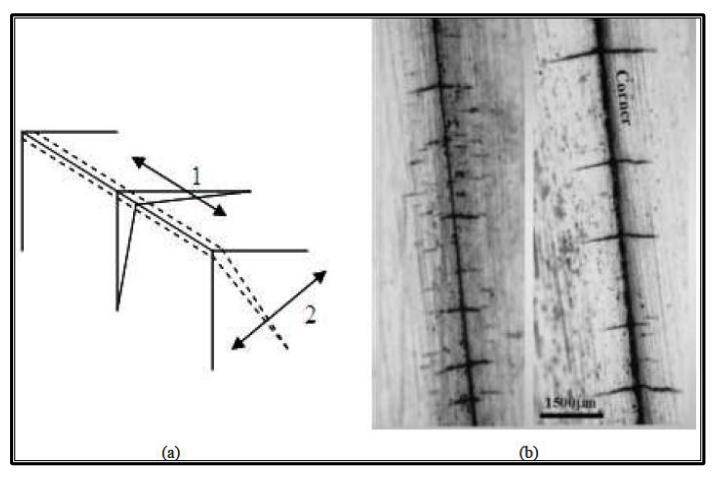

Figure 2.Direction of crack [18]

Moreover, die-casting dies are prone to high mechanical and thermal loads. Thermal fatigue cracking of dies which is caused by thermal cycling might considerably reduce the die lifetime. Cracks reduce the surface quality of dies and consequently the surface of castings will decline too. Previous studies have analysed thermal fatigue cracking of dies during the process of die casting aluminium alloys [7, 8, 22-24]. During the process cracks are identified and their size and location are measured. Thermal and mechanical loads produce high local stresses which make the surface to crack. First cracks emerge right after 2000 cycles and spread progressively with cycles as illustrated in Figure 2.[7, 18, 20, 21, 25].

\section{THERMAL FATIGUE IN DIE-CASTING DIES}

The thermal fatigue resistance of tool steels can be studied through differe tests. However, a majority of the studies involve the alternating immersion of samples in water and molten aluminium[26, 27] . This kind of experiment is like the actual high-pressure die-casting process, though it lacks repeatability. This is attributed to the sticking feature of the molten aluminum on the sample during testing which makes it the main weakness. Other researchers applied induction heating of samples surface followed by water cooling [28]. or gas cooling [26]. Researchers have also carried out tests by the applied conduction heating of samples, followed by water cooling of the tested surface [29]. Based on the findings of the previous studies, as shown in Table 1, the thermo-mechanical fatigue causes heat checks on the surface. The mechanical properties of the material grow instable in result of heating the die material. This problem and the surface treatment will be addressed in the following sections.

\section{THERMAL STRESS IN DIES}

The thermal stresses, which take place in the die, develop from the thermal gradient across the die area. The thermal gradient is made in he result of the heating and cooling of the surface during the ejecting, injecting, and lubricant spraying stages of the casting cycle. When the molten aluminum is injected into the die, the die surface heats up remarkably as opposed to the cooler underlying mass of the die. This sets up an initially steep thermal gradient. In the result, the surface enlarges more than the interior and because the interior is further massive, it does not allow the surface to expand. In consequence of this limitation, the surface undergoes compression. With an increase in the temperature, the yield strength of the material is lowered, and the compressive strains might grow plastic. The surface temperature decline quickly once a flow of heat is conducted to the lower layers. When the casting is ejected, cooling the surroundings from the surface, and the spray of die lubricants help to further decrease the

surface temperature.[28, 30]. If the surface cools more swiftly than the interior, the compressive strains are released and tensile strains might be produced. Figure 3 shows schematic diagrams of the temperature, stress and strain distributions experienced by casting dies both on heating (during casting) and cooling (after the casting has been extracted from the die) $[28,31,32]$. Each half of the casting cycle is portrayed by three schematic drawings. Figure 3 (a) through 3 (c) show the effect of increased surface temperature on the stress and strain distribution from surface to interior of the die material. Figure 3(d) through 3 (f) illustrate the subsequent stress and strain conditions which exist during the second or cooling period of the casting cycle. It becomes clear that the thermal gradient is a function of the thermal conductivity of the die material. Increased thermal conductivity will result in a lower therm al gradient and thus low er stresses and strains. 
Table 1. List of previous works conducted to prolong die life cycle.

\begin{tabular}{|c|c|c|c|}
\hline Ref & Materials & Fatigue properties & Finding \\
\hline [33] & AISI H13 tool steel & Thermal fatigue wear test & $\begin{array}{l}\text { Improve thermal fatigue properties } \\
\text { and reduce crack in semi-solid } \\
\text { processing. }\end{array}$ \\
\hline [14] & AISI H13 tool steel & $\begin{array}{l}\text { The thermal fatigue cracks of aluminium } \\
\text { alloy die casting is } \\
\text { analyzed. Immersion test apparatus. A } \\
\text { Finite Element } \\
\text { Analysis (FEA) of immersion test was } \\
\text { completed by ABAQUS software. }\end{array}$ & $\begin{array}{l}\text { The results showed a good thermal } \\
\text { fatigue resistance of the well } \\
\text { hardened H13 hot work tool steel. } \\
\text { The surface cracks growth increases } \\
\text { by surface oxidation. }\end{array}$ \\
\hline [1] & AISI H13 tool steel & $\begin{array}{l}\text { Previously, the standard thermal fatigue } \\
\text { immersion test was used to compare } \\
\text { steels. The thermal stresses were kept } \\
\text { equal for all the } 2 \text { " } 2 \text { 2" } 7 \text { 7"samples. }\end{array}$ & $\begin{array}{l}\text { Thermal fatigue samples have been } \\
\text { modified to incorporate stress } \\
\text { concentration factors typical to dies; } \\
\text { their effect of thermal fatigue } \\
\text { cracking is being assessed. The } \\
\text { experimental data will be } \\
\text { implemented to predict crack in die } \\
\text { casting. }\end{array}$ \\
\hline [34] & AISI H13 tool steel & $\begin{array}{l}\text { The wear test result shows that O-CrN- } \\
\text { H13 specimens possess the lowest } \\
\text { coefficient of friction. In addition, SEM } \\
\text { observation shows that only H13 } \\
\text { specimens have plough cracks on the } \\
\text { surface and other specimens show a very } \\
\text { shallow wear and tear on the surface } \\
\text { instead of Fe oxides wear test. }\end{array}$ & $\begin{array}{l}\text { Based on the results, the wear } \\
\text { resistance of AISI H13 can be } \\
\text { effectively improved by different } \\
\text { surface treatments. The lowest } \\
\text { coefficient of friction was also } \\
\text { noticed in the duplex surface } \\
\text { treatment of CrN coated with } \\
\text { oxynitriding. The coefficient of } \\
\text { friction was found } 0.28 \text {. }\end{array}$ \\
\hline [1] & C40 and AISI H13 steels & $\begin{array}{l}\text { The thermal fatigue test involved } \\
\text { immersion of samples into molten } \\
\text { aluminium, and quenched in ionised } \\
\text { water emulsion at } 17^{\circ} \mathrm{C} \text {. }\end{array}$ & $\begin{array}{l}\text { High surface roughness of laser } \\
\text { treated surface captured oxides and } \\
\text { carbides which might begin the } \\
\text { thermal fatigue failure. Cracks and } \\
\text { heat checks took place on the } \\
\text { carbides affected the area and } \\
\text { soldered surface. Laser treatment } \\
\text { parameter settings helped to } \\
\text { enhance thermal fatigue properties } \\
\text { during semisolid processing. }\end{array}$ \\
\hline
\end{tabular}




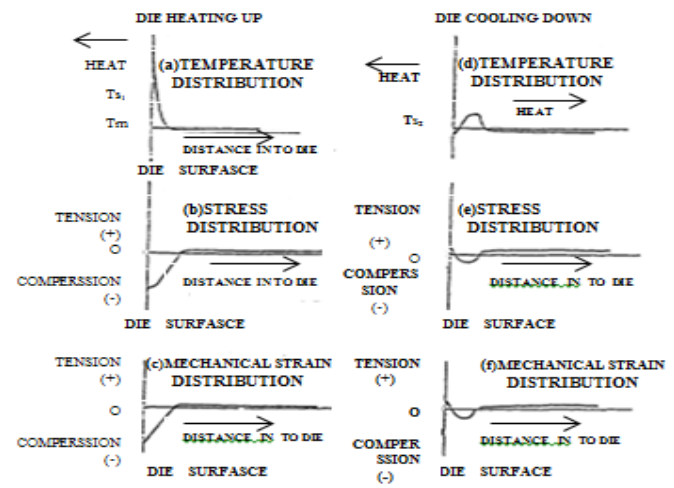

Figure3.Temperature, Stress and Strain Distributions when Dies are Exposured to Molten Metal [28]

During heating of the injection half of the die casting cycle, th e surface attempts to expand putting it in com pression with respect to the die interior, as shown in Figure 3(b). The corresponding compression strain is shown in Figure 3(c). The magnitude of the die surface stress is determined by the temperature gradient and the coefficient of thermal expansion of the die material. At first, the surface deform ation (strain) takes place within the die material elastic capabilities. However, if the integration of the temperature gradient and the widespread thermal expansion are high enough, the compression stress developed $\mathrm{w}$ ill exceed the elastic lim it of the die material as can seen in Figure 3(b), by the chang e in slope of the stress plot $\mathrm{n}$ ear the die surface[28].

\section{DIE MATERIALS ENHANCEMENT}

AISI H13 tool steel is commonly used for die casting dies, due to its good resistance against temparature, thermal fatigue, tense hardness, corrosion and wear. Extension of the die casting die life, and often apply different thermal and chemical treatments on the surface of the die. A previous study found that samples oxynitriding could pose a negative film, which has anti-corrosion properties contributed to better through corrosion test. Moreover, improving the surface properties of alloys and metals without any change in the bulk properties, like oxidation, hardness, corrosion, and corrosion resistance, and can show types of metal ions with an adjustable flow of ions and energy Indicates that the surface treatments of $\mathrm{CrN}$ coating also deposited with the planting of metal and carbon ions lead to condensation and phase shift in the nearsurface system to improve the corrosion resistance, abrasion resistance and fatigue strength significantly.Previous studies have suggested several methods to extend the service time of the casting dies such as nitriding [35], PVD/CVD coatings[36, 37], and laser surface engineering $[10,27,38,39]$. The findings of studies carried out by Lin et al. [40], Koneshlou et al. [37] and Bronfin et al. [26] recommended the use of four different layers to change the properties of metal in the best way possible [19]

\section{REFERENCES}

1. Collot, J., Review of New Process Technologies in the Aluminum Die-Casting Industry. Materials and Manufacturing Processes, 2001. 16(5): p. 595-617.

2. Avalle, M., et al., Casting defects and fatigue strength of a die cast aluminium alloy: a comparison between standard specimens and production components. International journal of Fatigue, 2002. 24(1): p. 1-9.

\section{CONCLUSION}

This study identifies and exemplifies the die casting process and the defects which appear during the casting. Detail is then given of ferrous casting alloys and non-ferrous casting alloys. Also, this paper focuses aluminium alloys, corrosion its corresponding mechanisms in the industry such as erosion, stress corrosion, and thermal fatigue has been expressed. At the same time, the protection of aluminium alloy corrosion (surface treatment/alteration, coating, etc.) is also presented. Because of the well-known characteristics of aluminium and its alloys (highly vulnerable to corrosion) and the extending challenges, the check of the working condition or surface treatment improved dies including cast as finer grain. New phases should be developed in a way to make the protection systems more practical, reliable, sustainable and cheaper and higher techniques need to be created to match with the practical applications. Furthermore, the prediction of defects represents the culmination of solidification modeling. It enables models to make practical contributions to real commercial processes, but it requires incorporating together and augmenting the models of almost every other aspect of casting simulation. Hot-tear, crack prediction requires accurate thermal and mechanical analysis, combined with criteria for embrittlement. With an advance in the computing power and software tools for computational mechanics, efficient analysis of fluid flow, strain, stress, temperature, deformation, and related phenomena in real casting processes has become highly possible. Computations are still affected and hampered by the limitations caused by mesh resolution, particularly for realistic threedimensional geometries and defect analysis. Regarding the thermal fatigue damage, the most important factor to initiate cracks is the steel softening. Once the conditions embolden at the lower temperature on the surface, less thermal fatigue damage are observed and consequently the die steel hardness and strength is preserved more. It seems like one of the conditions for the extension of the thermal fatigue cracking damage is a decrease in strength the crack. In addition, the maximum temperature in diecasting applications happens in thin sections where the capacity of the material to absorb and transfer the heat from the surface is extremely different. From another view, high temperature - long resident time conditions are important, since the significant with the die casting of large components, when the die is exposed to raised temperature for the longer duration of time. Previous studies have reported an important decrease of cracking when the cooling condition and lubricant is good. Furthermore, the results of the present study show that the existence of a temperature threshold, under which the thermal fatigue defect is least. Finally, controlling parameters like velocity melting metal, the temperature of the surface and surface treatment lead to reducing thermal fatigue defects.

3. Han, Q. and S. Viswanathan, Analysis of the mechanism of die soldering in aluminum die casting. Metallurgical and Materials ransactions A, 2003. 34(1): p. 139-146.

4. Schwam, D., et al., Effect of Design Factors on Thermal Fatigue Cracking of Die Casting Dies. Work Performed Under Contract DE-FC0700ID138486, US Department of Energy Assistant Secretary for Energy Efficiency and Renewable Energy, Washington, DC, October 2004, 2004. 
5. Fash, J., et al., Damage development during multiaxial fatigue of unnotched and notched specimens. ASTM special technical publication, 1988(942): p. 874-898.

6. Jhavar, S., C.P. Paul, and N.K. Jain, Causes of failure and repairing options for dies and molds: A review. Engineering Failure Analysis, 2013. 34: p. 519-535.

7. Sakhuja, A. and J.R. Brevick. Prediction of thermal fatigue in tooling for die-casting copper via finite element analysis. in AIP Conference Proceedings. 2004. IOP INSTITUTE OF PHYSICS PUBLISHING LTD.

8. Shi, Q., Prediction of thermal distortion and thermal fatigue in shot sleeves. 2002, The Ohio State University.

9. Obiekea, K.N., S.Y. Aku, and D.S. Yawas, Effects of Pressure on the Mechanical Properties and Microstructure of Die Cast Aluminum A380 Alloy. Journal of Minerals and Materials Characterization and Engineering, 2014. 02(03): p. 248-258.

10. Otarawanna, S., High Pressure Die Casting of Aluminium and Magnesium Alloys: Formation of Microstructure and Defects. 2009.

11. Bai, Y. and H. Zhao, Tensile properties and fracture behavior of partial squeeze added slow shot die-cast A356 aluminum alloy. Materials \& Design, 2010. 31(9): p. 4237-4243.

12. ElTobgy, M.S., E. Ng, and M.A. Elbestawi, Finite element modeling of erosive wear. International Journal of Machine Tools and Manufacture, 2005. 45(11): p. 1337-1346.

13. <232 Materials_for_Automobiles 14.pdf>.

14. Klobčar, D., et al., Thermo fatigue cracking of die casting dies. Engineering Failure Analysis, 2012. 20: p. 43-53.

15. Abed, D.E.J., <42 The Influence of Different Casting Method on.pdf>. International Journal of Engineering \& Technology IJET-IJENS 2011. Vol: 11 No: 06: p. 8.

16. Lus, H.M., Effect of casting parameters on the microstructure and mechanical properties of squeeze cast A380 aluminum die cast alloy. ovove Materialy, 2012. 50(4): p. 243-250.

17. Sadowski, T. and P. Golewski, The influence of quantity and distribution of cooling channels of turbine elements on level of stresses in the protective layer $T B C$ and the efficiency of cooling. Computational Materials Science, 2012. 52(1): p. 293-297.

18. David Schwam, P. and X. Zhu Sr, Energy Saving Melting and Revert Reduction Technology: Improved Die Casting Process to Preserve the Life of the Inserts. 2012, Advanced Technology Institute.

19. Fazarinc, M., et al., Thermal fatigue properties of differently constructed functionally graded materials aimed for refurbishing of pressure-die-casting dies. Engineering Failure Analysis, 2012. 25: p. 238-249.

20. Koutiri, I., et al., High cycle fatigue damage mechanisms in cast aluminium subject to complex loads. International Journal of Fatigue, 2013. 47: p. 44-57.
21. Hussein, A.M., et al., A review of forced convection heat transfer enhancement and hydrodynamic characteristics of a nanofluid. Renewable and Sustainable Energy Reviews, 2014. 29: p. 734-743.

22. Kadiri, H.E., et al., Identification and modeling of fatigue crack growth mechanisms in a die-cast AM50 magnesium alloy. Acta Materialia, 2006. 54(19): p. 5061-5076.

23. Kowanaga, S., T. Konaga, and M. Nakamura, Initiation and Propagation of Heat Checking and Variation of Residual Stress in Aluminum Die Casting Dies. J. Jpn. Die Cast. Assoc., 1989(90): p. 1-9.

24. Naimi, S. and S.M. Hosseini, Tool Steels in DieCasting Utilization and Increased Mold Life. Advances in Mechanical Engineering, 2015. 7(1): p. 286071-286071.

25. Heim, D., F. Holler, and C. Mitterer, Hard coatings produced by $P A C V D$ applied to aluminium die casting. Surface and coatings Technology, 1999. 116: p. 530-536.

26. Bronfin, B., et al. Metallurgical background to the development of creep resistant gravity casting magnesium alloys. in Magnesium Technology 2005, Proceedings of the Symposium Sponsored by the Magnesium Committee of the Light Metals Division (LMD) of TMS with the International Magnesium Association. 2005. Minerals, Metals \& Materials Society Warrendale.

27. Anderson, B., Die Casting Engineering: a hydraulic, thermal and mechanical process. 2005, Marcel Dekker NY.

28. Wallace, J., Thermal Conditions in the Die. Foundry, 1968. 96(10): p. 176-179.

29. Totten, G.E., K. Funatani, and L. Xie, Handbook of metallurgical process design. 2004: CRC press.

30. Verran, G.O., R.P.K. Mendes, and M.A. Rossi, Influence of injection parameters on defects formation in die casting Al12Si1,3Cu alloy: Experimental results and numeric simulation. Journal of Materials Processing Technology, 2006. 179(1-3): p. 190-195.

31. Doehler, H.H., Die casting. 1951: McGraw-Hill.

32. Abdelatif, A.O., J.S. Owen, and M.F.M. Hussein, Modelling the prestress transfer in pre-tensioned concrete elements. Finite Elements in Analysis and Design, 2015. 94: p. 47-63.

33. Aqida, S.N., et al., Thermal fatigue properties of laser treated steels. International Journal of Material Forming, 2010. 3(1): p. 797-800.

34. Chang, S.-H., K.-T. Huang, and Y.-H. Wang, Effects of thermal erosion and wear resistance on AISI H13 tool steel by various surface treatments. Materials Transactions, 2012. 53(4): p. 745-751.

35. Beeley, P., Foundry technology. 2001: ButterworthHeinemann.

36. Blair, M. and T.L. Stevens, Steel castings handbook. 1995: ASM International.

37. Koneshlou, M., K.M. Asl, and F. Khomamizadeh, Effect of cryogenic treatment on microstructure, mechanical and wear behaviors of AISI H13 hot work tool steel. Cryogenics, 2011. 51(1): p. 55-61. 
38. Parashar, B.N. and R. Mittal, Elements of manufacturing processes. 2002: PHI Learning Pvt. Ltd.

39. Fisher, K. and W. Kurz, Fundamentals of solidification. Trans Tech Publications, 1986.

40. Lin, J., et al., Design methodology for optimized die coatings: The case for aluminum pressure diecasting: Invited paper B7-1-1, ICMCTF, presented Monday May 2nd, 2005, San Diego. Surface and Coatings Technology, 2006. 201(6): p. 2930-2941. 